\title{
Re-booting gender in communication research and practice: a translational approach. ECREA 2018 special panel report
}

\author{
Claudia Padovani* , University of Padova \\ Karen Ross, Newcastle University \\ with Monika Djerf-Pierre and Maria Edström, Gothenburg University \\ *Corresponding author: claudia.padovani@unipd.it
}

\section{Note}

Invited report for the Thematic Section on ECREA 2018 devoted to the $7^{\text {th }}$ European Communication Conference of the European Communication and Research Association (ECREA), held in Lugano from October $31^{\text {st }}$ to November $3^{\text {rd }}, 2018$.

\section{Overview and aims}

The special panel "Re-booting gender in communication research and practice: a translational approach" comprised a group of colleagues who are working together on two different projects around gender equality in the media, along with a contributor from the European Institute for Gender Equality. The panel responded to the conference theme in several ways, not least by placing gender equality front and centre as an important but often neglected element of media policy and practice. We argue that issues of gender are located at both the centre and the periphery of media and communication research in terms of content (representation), production (employment), policy (structure) and ownership (political economy). While all these aspects have been topics of significant research interest over the past few decades, a consideration of the ways in which gender is a differentiating feature of media content and media practice has often been a glaring omission in research design.

The panel's use of the term 're-boot' in its title was deliberate, encouraging the audience to explore new ways to think about gender equality and the media through the translation and re-interpretation of communication research findings. While gender as a term has always been contested and controversial, the two projects which constituted the substantive content of the panel are more concerned with the material and experiential differences between women and men in relation to the media which are the result of their sex and not their competence. As we discuss below, we did this through a presentation and demonstration of a novel web platform focused on Advancing Gender Equality in Media Industries (AGEMI) and a consideration of a new project (Comparing Gender and Media Equality across the Globe: GEM) which is re-interrogating gender-related data drawn from a range of international research surveys, to explore why the media landscape looks the way it does, in Europe and beyond.

We were keen to highlight the value of adopting a global and multi-dimensional approach to research in the field, which implies the translation, integration and interpretation of data, languages and innovative methodologies. The two projects do this in different ways. The AGEMI project's web platform (www.agemi-eu.org) includes a range of materials in different languages and the video lecture elements of the learning resources are all sub-titled in English, French and Spanish, as are a set of interviews we have conducted with media experts, professionals and policy-makers. The GEM project brings together a range of European and international datasets to constitute a 'super-dataset' which draws on data from around the world. 
Another important aspect of our translational approach in the panel was to include a specific policy dimension by inviting a speaker from the European Institute for Gender Equality (Mira Banerjee, Head of Knowledge Management and Communications) to contribute. She was able to show the ways in which EIGE both commission original research from the academic community but also how they use (translate) research findings to inform their own policy recommendations. Understanding those relationships and how to further develop them is a crucial aspect for all academic researchers who want their work to make a difference in the real world, for real people and to promote real change.

\section{Presenters}

Claudia Padovani, University of Padova, Italy and Karen Ross, Newcastle University, UK who chaired the panel. Our other speakers were: Maria Edström and Monika Dierf-Pierre, University of Gothenburg, Sweden and Mira Banerjee, European Institute for Gender Equality, Lithuania.

\section{Topics discussed}

The panel opened with a presentation from Mira Banerjee who discussed the role of European institutions in enhancing gender equality in the EU and the importance of working with academic, civil society and media organisations in order to translate research findings - both in terms of language and discipline - and integrate them into actionable policy. It is widely acknowledged that a gap persists between academic research and policy-makers, thus hindering the efficient use of research findings in informing European gender equality policies. EIGE is striving to bridge that gap by working in collaboration with academic researchers, as well as with other civil society organisations, media and European agencies, to ensure that research findings reach the largest possible audience to maximise impact, not least through paying attention to the style and accessibility of the publications they produce and the online resources they create. EIGE's website is one of its primary means through which to access examples of good practice, guidance, reports and briefings on multiple subjects and domains, including the media, all of which are refracted through a gendered lens. What was interesting about Mira's presentation was that although EIGE has been in existence since 2010, a number of people in the audience had no knowledge of the organisation. This suggests that we need to create more opportunities for intersectoral engagement since the discussion during the panel was lively and engaging and several business cards were swapped: the ECREA conference has thus been central in providing a space for communication around research and its translation in relation to policy development.

The substantive discussion, however, was focused on the two projects - Advancing Gender Equality in Media Industries (AGEMI); and Comparing Gender Equality in the Media (GEM) - both of which are Europe-focused. They both offer new resources to advance gender equality in the media through learning materials (an online module), a Resources Bank of Good Practices (AGEMI) and a new database (GEM), all of which are fully open access to all interested stakeholders.

\section{AGEMI - Advancing Gender Equality in Media Industries}

AGEMI takes an innovative and integrated approach to combating gender stereotypes and promoting equal opportunities, by designing educational and knowledge-based resources aimed at inspiring and informing both students and media professionals and developing a Resources Bank of Good Practices. AGEMI is a very good example of a research-informed and collaborative action project, using the findings of decades of research on the broad topic of gender and in/equality in the media and translating it into, among other things, a learning resource to raise 
awareness of both the problems of gender in/equality in the media but also the range of good practices which have been created to challenge them. AGEMI's consortium members are the Universities of Newcastle (UK), Padova (Italy) and Gothenburg (Sweden), together with the European Federation of Journalists (EFJ) and the Permanent Conference of Mediterranean Public Sector Audiovisual Media (COPEAM). It was co-funded by the Rights, Equality and Citizenship Programme of the European Union. By taking an integrated and multi-stakeholder approach, we hope that students and practitioners will develop strategies to foster gender-sensitive practices. The learning resources comprise a set of ten thematic units which discuss a range of issues including representation, the gendered newsroom, digital technology, advocacy and policy-making, all of which then link to the good practices that have been collected in the Resources Bank. Each unit includes a number of video lectures, interviews with experts, advocates and policy-makers, a set of additional textbased resources and a set of activities. All the learning resources can be viewed as streamed content or downloaded for later viewing and use.

The project's web platform also makes visible the considerable breadth and depth of interventions which have been developed to combat gender inequality in the media sector, brought together in the Resources Bank of Good Practices and in the interactive GEMap where over one hundred relevant organizations are plotted on a world map. These openly accessible resources (www.agemi-eu.org) are structured according to a theoretically sound framework for the collection of good practices and engaged actors which can be visualized and explored by country, type and inequality issue addressed.

The project commenced in 2017 and concluded in 2019, just before the Beijing Platform for Action celebrates its $25^{\text {th }}$ anniversary in 2020, and has evolved as part of an open dialogue with ongoing international efforts to mainstream media gender equality worldwide, such as the Global Alliance for Media and Gender (GAMAG) and the UNESCO's UniTWIN Network for Gender Media and ICTs. This dialogue has provided further opportunities to link centres and peripheries of relevant practice-based knowledges, within and beyond academic communities. Furthermore, opportunities have emerged to collaborate with other EU-funded projects- such as the Erasmus Virtual Exchange (EVE) project (https:// europa.eu/youth/erasmusvirtual_en), which focuses on innovative forms of education through the use of online teaching modes that foster transnational knowledge sharing and intercultural encounters amongst young people from Europe and the Mediterranean region. Engaging in such multi-stakeholder dialogues - involving researchers, practitioners and policy-shapers - also supports the adoption of an integrated approach to translation, including interpretation of data, use of different languages and development of tools and methods for sharing the expertise embedded in the project.

\section{GEM - Comparing Gender and Media Equality across the Globe}

Gender equality in and through the media is a global human rights issue, with broad implications for media content (the representation of women and men), media organizations (equal access to and status in media professions), and media access and use. A number of studies conducted by the Global Media Monitoring Project (GMMP), European Institute for Gender Equality (EIGE), and the International Women's Media Foundation (IWMF) have charted the progress - or lack thereof - over the last decades. A significant amount of descriptive data is thus available for the study of gender equality in media content and media organizations both across countries and over time. This creates new opportunities for innovative research in the field. The comparative and cross-national project - Comparing Gender and Media Equality across the Globe: a Cross-National Study of the Qualities, Causes and Consequences of Gender Equality in and through the News Media 
(the GEM project - Gender Equality Media) - seeks to advance the media research agenda by drawing from previously collected data to answer longstanding questions in feminist media research. The aim is to conduct systematic, empirical (statistical) analyses of both the causes and consequences of media and gender equality in different countries across the globe. The project addresses three key questions: (1) Qualities: how has gender equality in news media content, media organisations and media access and use developed over time and across different countries and how are the different aspects related? (2) Causes: to what extent can differences in gender equality in the media be explained as a result of variations in economic, political, social, and cultural factors in society, as well as factors pertaining to differences in media systems? (3) Consequences: to what degree is gender equality in the media related to other aspects of a good society such as democracy, media freedom, economic and social development and good government, the latter particularly with regard to freedom from corruption?

The basis for comparison is data collected at the national level but the goal is to go beyond descriptive analyses of single countries or regions; firstly, by bringing together, complementing, and reanalysing existing data on media/gender equality in media content, in media organizations, and with regard to media access and use; second, by combining the datasets on gender equality with existing sources of empirical data on the essential structural and cultural factors in society and in the media systems, which can explain the differences in media/gender equality between countries; and third, by employing advanced quantitative methods for analysing data and testing statistical relationships. This will further our knowledge of how various factors contribute to increasing equality, which factors are necessary and/or sufficient, as well as understanding the societal consequences of the lack of gender equality in the media.

The project is funded by the Swedish Research Council (2016-2020) and conducted by a Swedish research team from the University of Gothenburg (Monika Djerf-Pierre, Project Leader, Maria Edström and Mathias Färdigh) in collaboration with four international partners: Carolyn Byerly (Howard University), Karen Ross (University of Newcastle), Claudia Padovani (University of Padova), and Sarah Macharia (WACC).

At the end of the special session, we invited participants to consider how they could use the resources we have developed in AGEMI and GEM in their own teaching, training and research projects and in particular, how they could be incorporated into existing teaching and research projects, or inform new ones.

\section{Conclusion and reflections}

For AGEMI, all the resources we have developed are accessible online and available to download for teachers and trainers to integrate as they wish. They also formed the basis of two online courses managed by the EU-funded Erasmus Virtual Exchange (EVE) project, which ran in the autumn of 2018 and the summer of 2019. The GEM team expect the database and codebook to be available in spring 2020 when it can then be interrogated by researchers to answer new questions.

All resources are publicized and promoted across international academic and professional networks, creating synergies that we hope will contribute to translate theoretical and practical knowledges into gender-aware media operations. Free and open access to such resources is not only a distinctive feature of both projects, it is also a global invitation to explore new ways of thinking about gender equality and the media and to transform media-related practices. Students and researchers, as well as teachers and trainers, can find inspiration to enrich their activities and develop a more comprehensive understanding of gendered dynamics in and through the media. Media professionals, media companies and advocacy groups will find easy-to-access information and data to rethink their own working modes 
and implement principles of inclusion, diversity and equal opportunities.

\section{Panel overview}

\section{Panel Title}

Re-booting gender in communication research and practice: A translational approach

\section{Panel organizers}

Claudia Padovani (University of Padova), Karen Ross (Newcastle University) Date and location

Thursday, $1^{\text {st }}$ November 2019, 11:00-12:30, Villa Ciani, Room 015

The role of institutions in promoting gender equality: the European Institute for Gender Equality (EIGE).

Banerjee, M. (Head of Knowledge Management and Communications, EIGE, Vilnius, Lithuania)

The "Advancing Gender Equality in Media Industries" project: An introduction.

Ross, K. (Professor of Gender and Media, Newcastle University, School of Arts and Cultures, Newcastle upon Tyne, United Kingdom)
The "Advancing Gender Equality in Media Industries" project: Sharing good practices and developing policies .

Padovani, C. (Associate Professor, University of Padova, DSPGI Department of Politics, Law and International Studies, Padova, Italy)

Research collaboration and engagement to advance the global agenda on gender and media.

Edstrom, M. (Associate Professor, University of Gothenburg, Department of Journalism, Media and Communication (JMG), Gothenburg, Sweden)

The GEM project - making new use of existing data to answer longstanding questions in gender and media equality research. Djerf Pierre, M. (Professor of Journalism and Mass Communication, University of Gothenburg, Department Journalism Media and Communication (JMG), Gothenburg, Sweden) 
